\title{
CARBON DIOXIDE EXCHANGE IN LICHENS: RELATIONSHIP BETWEEN THE DIFFUSIVE RESISTANCE OF CARBON DIOXIDE AND WATER VAPOUR
}

\author{
T. G. A. GREEN` and W. P. SNELGAR*
}

\begin{abstract}
Gaseous diffusion resistances for carbon dioxide and water vapour, thallus water content and thallus water potential were experimentally determined on species of the Stictaceae. The diffusion resistance to water loss was high only at low water contents and correlated closely with thallus water potential. Carbon dioxide diffusion resistances, however, were high at both low and high water contents and, even at medium water contents, were still an order of magnitude greater than the water resistance. These results indicate that carbon dioxide and water vapour exchange occur by different pathways in these lichens. Consequently it is suggested that the lichens have structural adaptations which separate the functions of water uptake, water storage and carbon dioxide exchange.
\end{abstract}

\section{Introduction}

In vascular plants, particularly angiosperm leaves, diffusive resistances have proved to be of considerable significance in the study of photosynthesis and water relations (Jarvis 1971). It is unfortunate that the study of carbon dioxide and water vapour diffusive resistances has been given little emphasis in lichen physiology. Published estimates of carbon dioxide diffusion resistances have only recently appeared for lichens, the first being that of Collins \& Farrar (1978) who obtained a value of $138 \mathrm{~s} \mathrm{~cm}^{-1}$ for Xanthoria parietina. Studies on large foliose members of the New Zealand Stictaceae have shown that minimum carbon dioxide resistances varied from 30 to $70 \mathrm{~s} \mathrm{~cm}^{-1}$ and that increases may occur at both high and low water contents (Snelgar et al. 1981b). Diffusive resistances to water loss have rarely been calculated but very low values in the range of 0.035 to $0.40 \mathrm{~s} \mathrm{~cm}^{-1}$ at medium thallus saturation found by Larson (1979) would be typical (Harris 1976, Larson \& Kershaw 1976).

There have been no published comparisons of the magnitudes of the carbon dioxide and water diffusive resistances at different thallus water contents. Collins $\&$ Farrar (1978) make the point that 'one consequence of a high $r_{\mathrm{c}}$ (cortex resistance) for carbon dioxide is a similarly high resistance to water loss and hence, during desiccation, the rate of loss of water from algal cells will be reduced'. This is a view that originates from studies of higher plant stomatal diffusion resistances where there is a simple linear relationship between the two resistances. Such a relation holds only where both the carbon dioxide and water are diffusing in air and would not be expected where carbon dioxide is moving in solution. The latter situation is found in the cuticular layers of leaves where the water and carbon

\footnotetext{
^Biological Sciences, Waikato University, Private Bag, Hamilton, New Zealand.
} 
dioxide resistances differ considerably. The water moves by mass flow and evaporates directly from the surface whilst the carbon dioxide has to diffuse slowly through the water to the chloroplasts (Jarvis 1971). A similar situation might be expected to occur in the cortical layers of lichens where few gaseous pathways appear to exist (Collins \& Farrar 1978, Lange 1980). In this study a comparison of the water and carbon dioxide diffusion resistances was made at various water contents in an attempt to clarify the relationship between the two.

\section{Materials and Methods}

Abbreviations: $\sum r_{\mathrm{CO}}$, total $\mathrm{CO}_{2}$ diffusion resistance, $\mathrm{s} \mathrm{cm}{ }^{-1} ; \sum r_{\mathrm{H}, \mathrm{O}}$, total diffusion resistance for water loss, $\mathrm{s} \mathrm{cm}{ }^{-1} ; r_{\mathrm{c}}$, part of $\sum r_{\mathrm{CO}}$, attributed to cortex of lichen, $5 \mathrm{~cm}^{-1} ; \mathrm{RH}$, relative humidity, $\%$; $\psi$; water potential, bar; NP, net photosynthesis; $\mathrm{mg} \mathrm{CO}_{2}$ per gram dry weight per $\mathrm{h}$.

Material: Specimens of Sticta latifrons Rich., Pseudocyphellaria colensoi (Bab., Vainio, P. billardierii (Del.) Räsanen and P. homoeophylla (Nyl.) Dodge were collected from the Waikareiti area of the Urewera National Park (NZMS 1 N96 619437), North Island, New Zealand. Lichens were stored air dry in the dark over silica gel for a maximum of 3 weeks.

Carbon dioxide resistance determinations: these were carried out as described in Snelgar et al. $(1981 b)$ and involved the determination of the slope of net photosynthesis rate against $\mathrm{CO}_{2}$ concentration at several water contents. All measurements were made at a saturating light intensity of $150 \mu \mathrm{E} \mathrm{m}^{-2} \mathrm{~s}^{-1}$ and under microaerobic conditions (1\% oxygen), in order to minimize photorespiratory activity.

Diffusion resistance to water loss: This was determined with a $\Delta T$ series 2 automatic porometer, using the standard methods of measurement and calibration as described by the manufacturer. Lichen thalli were allowed to dry down under normal laboratory conditions or were equilibrated at fixed relative humidities $(\mathrm{RH})$ generated by saturated salt solutions in a desiccator at $20^{\circ} \mathrm{C}$. Measurements were limited to low and medium water contents since the porometer is not designed for use where surface water is present. Water potentials were obtained from standard tables (Slavik, 1974), and water contents are expressed as mg water per $m g$ thallus dry weight.

Photosynthesis rates: NP determinations were made using an ADC series 225 infra-red gas analyser in a closed loop system described in Snelgar, et al. (1981b). All determinations were at $350 \mu 1 \mathrm{CO}_{2} 1^{-1}, 16^{\circ} \mathrm{C}$ and were carried out at several thallus water contents starting with a saturated lichen thallus which was dried slightly between each determination. All results are expressed as $\mathrm{mg}$ $\mathrm{CO}_{2}$ fixed per gram dry weight per hour $\left(\mathrm{mg} \mathrm{CO} \mathrm{CO}^{-1} \mathrm{~h}^{-1}\right)$.

\section{Results}

The relationships between water potential $(\psi)$ and water content for Sticta latifrons, Pseudocyphellaria colensoi, P. billardierii and P. homoeophylla all show a similar pattern in which there is at first a slow decrease in $\psi$ with decrease in thallus water content changing to a more rapid decrease below a water content of about 0.5 (Fig. 1). P. colensoi is distinguished from the other species by a lower water content for any particular $\psi$; this is clearly seen at $\psi=-50$ bar where it has a water content of about $60 \%$ of the other species (Fig. 1B). A similar relationship is found between $\sum r_{\mathrm{H}_{2} \mathrm{O}}$ and thallus water content for $S$. latifrons and $P$. homoeophylla (Fig. 2). Figure $2 \mathrm{~A}$ was constructed from $\sum r_{\mathrm{H}_{\mathrm{O}}}$ values obtained separately from the top and bottom surfaces of thalli of $S$. latifrons that were allowed to dry in air and measured at various water contents, and also from the top surface of thalli equilibrated to constant water content at several values of $\mathrm{RH}$. A single line is a good fit for all data points and no detectable differences in $\sum r_{\mathrm{H}_{2} \mathrm{O}}$ exist between top and bottom thallus surfaces or between thalli of similar 


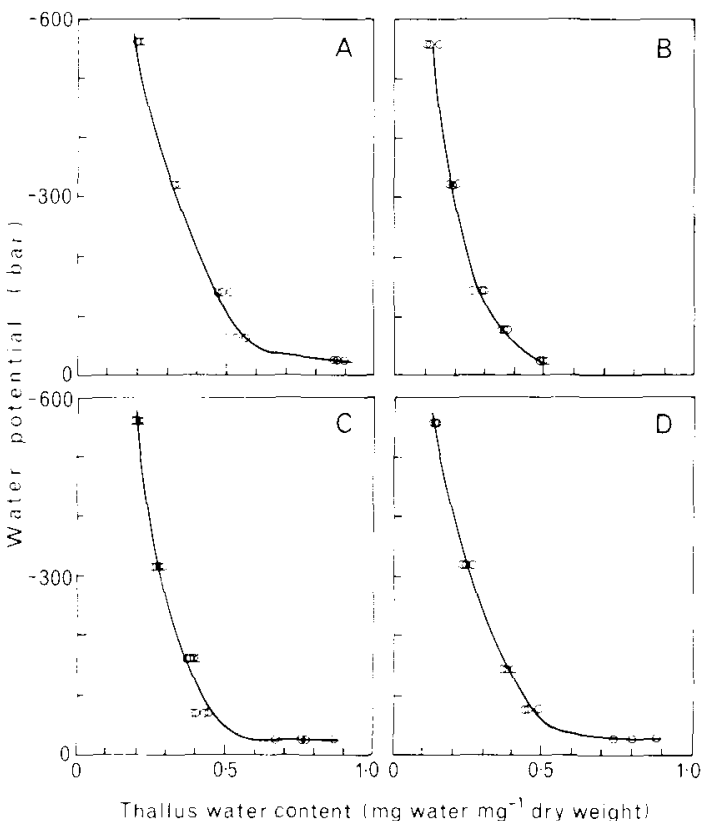

FIG. 1. Relationship between water potential $\left(\psi\right.$, bar) and thallus water content (mg water $\mathrm{mg}^{-1} \mathrm{dry}$ weight for: A, Sticta latifrons; B, Pseudocyphellaria colensoi; C, P. billardierii; D, P. homoeophylla. Thalli were allowed to equilibrate to constant thallus water content at a known RH generated by a standard salts solution at $20^{\circ} \mathrm{C}$.

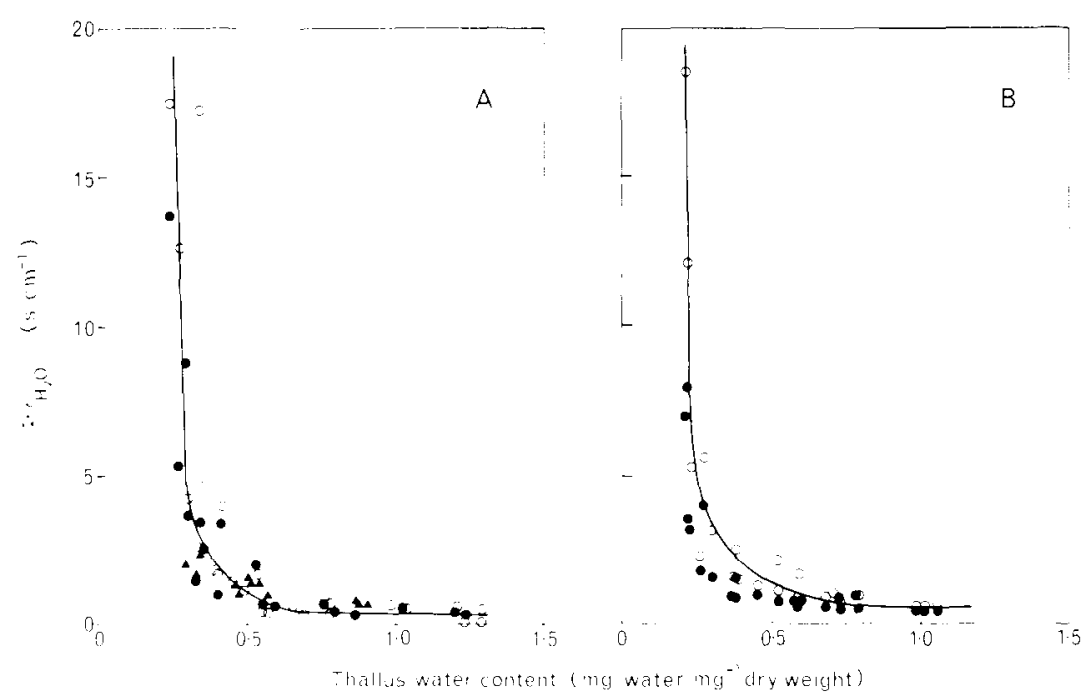

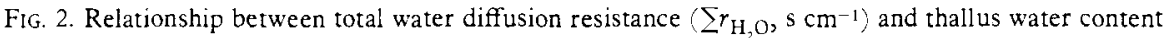
'mg water $\mathrm{mg}^{-1} \mathrm{dry}$ weight) for: A, Sticta latifrons; and B, Pseudocyphellaria homoeophylla. $\sum r_{\mathrm{H}_{3} \mathrm{O}}$ measured on the upper (-) and lower (O) surfaces of thalli allowed to dry in air; or on the upper surface $(\boldsymbol{\Delta})$ of thalli equilibrated to constant thallus water content at a fixed $\mathrm{RH}$. 
water content obtained by drying or equilibration. The porometer could be used only at low and medium water contents since at higher water contents liquid water was present. However, for this reason, at high water contents $\sum r_{\mathrm{H}_{2} \mathrm{O}}$ would be expected to be identical to, or lower than, the values at the highest water content measured. The results of Harris (1976), Larson \& Kershaw (1976) and Larson (1979) tend to substantiate this extrapolation.

Figures $3 \mathrm{~A}-\mathrm{B}$ are a summary for Sticta latifrons and $P$. homoeophylla of the relationships between net photosynthesis (NP), $\sum r_{\mathrm{CO}}, \sum r_{\mathrm{H}_{2} \mathrm{O}}, \psi$ and thallus water content. Both graphs show very similar patterns with $-\psi$ and $\sum r_{\mathrm{H}, \mathrm{O}}$ increasing steeply at low water contents, $\sum r_{\mathrm{CO}_{2}}$ increasing at both low and high water contents and NP almost an inverse of $\sum r_{\mathrm{CO}}$. When comparing $\sum r_{\mathrm{H}_{2} \mathrm{O}}$ and $\sum r_{\mathrm{CO}_{1}}$ it is important to note that they differ markedly at high water contents where $\sum r_{\mathrm{H}_{0}}$ is low but $\sum r_{\mathrm{CO}_{2}}$ rises rapidly, and that $\sum r_{\mathrm{CO}_{2}}$ has considerably higher values than $\sum r_{\mathrm{H}, \mathrm{O}}$ at any particular water content. At water contents of $1.0 \sum r_{\mathrm{CO}_{2}}$ is 180 times greater than $\sum r_{\mathrm{H}_{2} \mathrm{O}}$. At no water content is $\sum r_{\mathrm{CO}_{2}}$ less than a factor of ten greater than $\sum r_{\mathrm{H}_{2} \mathrm{O}}$.

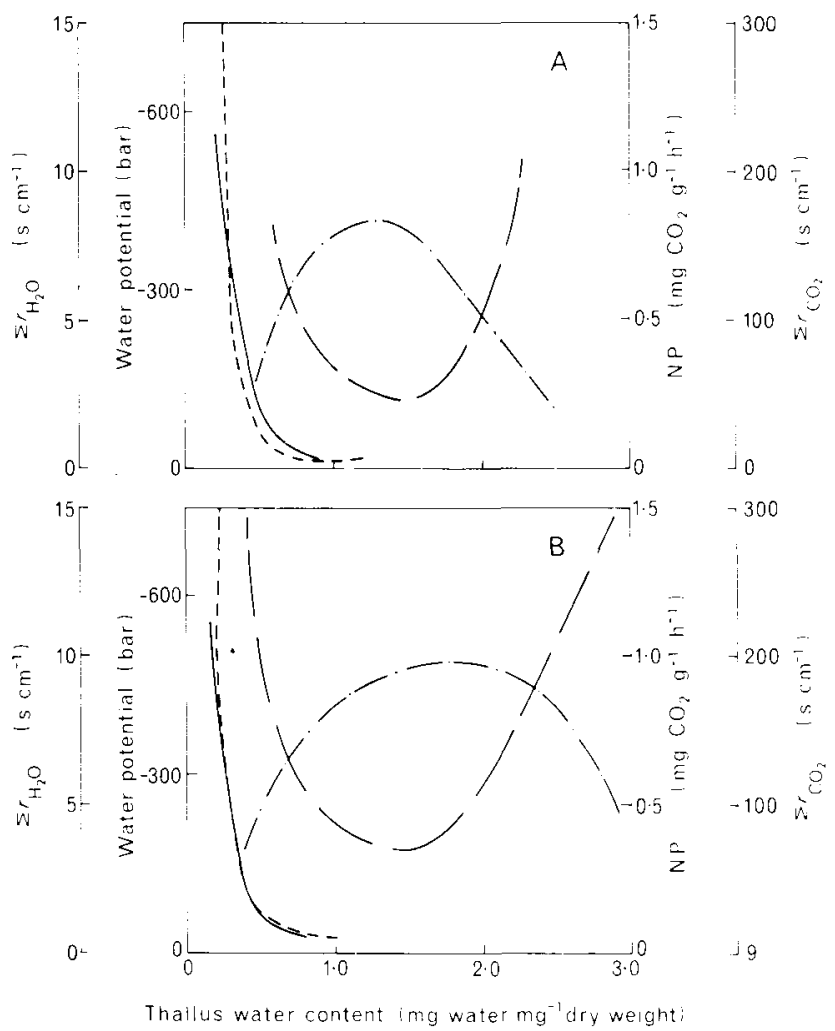

FIG. 3. Summary of the relationship between water potential $(\psi$, bar $)$, total water diffusion resistance

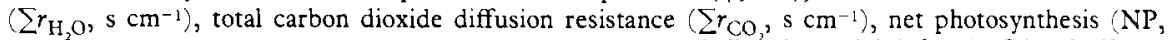
$\mathrm{mg} \mathrm{CO} \mathrm{g}^{-1} \mathrm{~h}^{-1}$ ) and thallus water content ( $\mathrm{mg}$ water $\mathrm{mg}^{-1}$ thall us dry weight) for: A, Sticta latifrons; and $\mathrm{B}$, Pseudocyphellaria homoeophylla. -,$\psi ;----, \sum r_{\mathrm{H}_{2} \mathrm{O}} ;--, \sum r_{\mathrm{CO}} ;-\cdot-\cdot-$, NP. Values for $\psi$ and $\sum r_{\mathrm{H}_{2} \mathrm{O}}$ are from Figs 1 and 2, respectively. The values for $\sum r_{\mathrm{CO}_{2}}$ and NP are from Snelgar 


\section{Discussion}

The results summarized in Fig. 3 indicate that the resistance to water loss is determined by the physical properties of the thallus, in particular the thallus water potential. This result is in accord with those of Harris (1976), and Snelgar \& Green (1981) which indicate that there are no modifications to limit surface water loss in lichens. A similar direct relationship between thallus water potential and the resistance to water loss has been suggested for intertidal algae (Jones $\&$ Norton 1979).

$\sum r_{\mathrm{CO}_{2}}$ is a composite resistance made up of the gaseous diffusion resistance plus cellular aqueous diffusion and biochemical resistances. However the presence of cyphellae or pseudocyphellae in these lichens results in the gaseous diffusion resistance forming the major part of $\sum r_{\mathrm{CO}}$ even at optimum thallus water content (Snelgar et al. 1981a). The data on $\sum r_{\mathrm{CO}_{2}}$ show a more complex situation than found for $\sum r_{\mathrm{H}_{\mathrm{O}} \mathrm{O}}$ with high resistances occurring at both low and high thallus water contents. The increased $\sum r_{\mathrm{CO}}$ at low thallus water contents may be attributed to a biochemical inhibition resulting from the low water potentials as indicated by the results of Cowan et al. (1979) and Green \& Snelgar (1981). Increased $\sum r_{\mathrm{CO}_{2}}$ at high thallus water contents appears to be entirely the result of increased resistance to gaseous diffusion of carbon dioxide probably caused by a partial decrease in volume of the gaseous diffusion pathways by water infiltration (Green \& Snelgar 1981, Snelgar et al. 1981b, Lange \& Tenhunen 1981). Carbon dioxide diffusion in water is so much slower than diffusion in air that even a short water diffusion path results in a marked resistance increase. The results demonstrate that the relationship between $\sum r_{\mathrm{CO}_{2}}$ and $\sum r_{\mathrm{H}_{2} \mathrm{O}}$ in lichens is complex and cannot be interpreted as a simple linear relationship as found for the stomata of higher plants. Even at low water contents where the responses of both parameters are similar $\sum r_{\mathrm{CO}}$ values are up to 160 -fold higher than $\sum r_{\mathrm{H}_{2} \mathrm{O}}$ values. Further evidence of the lack of correspondence is found at higher water contents where $\sum r_{\mathrm{CO}_{2}}$ increases drastically when $\sum r_{\mathrm{H}_{2} \mathrm{O}}$ must be low. These marked differences between $\sum r_{\mathrm{CO}_{2}}$ and $\sum r_{\mathrm{H}_{2} \mathrm{O}}$ strongly suggest that carbon dioxide and water follow different diffusion pathways in the lichen. Circumstantial evidence obtained by using a split cuvette (Green et al. 1981) suggests that carbon dioxide diffuses through the cyphellae or pseudocyphellae of the lower surface of these lichens with the major diffusion resistance lying in the gas exchange structure itself (Snelgar et al. 1981a).

The porometer evidence presented here indicates that water loss may occur at identical rates by evaporation from both upper and lower surfaces with the water moving by mass flow through the cortex. The situation would be analogous to a higher plant leaf that exchanged carbon dioxide through the stomatal pores of the lower surface but lost water from its entire surface. Normally such a leaf would have a 'waterproof' cuticle that prevented surface water loss and confined it also to the stomatal pores. Such a situation is not feasible for lichens which do not have a continuous internal supply of water from a vascular system. Lichens must also be capable of being moistened by rain or mist and may need to utilize external water reserves (Snelgar \& Green 1981b). Such a low resistance to water loss also means that there is little advantage, in terms of water loss rate, in internal rather than external water storage.

The stomata of higher plant leaves perform both carbon dioxide and water vapour exchange functions with a consequent close relation between the carbon 
dioxide and water vapour gaseous diffusion resistances. The evidence presented here indicates that this could not be so for the lichens studied and that carbon dioxide and water vapour do not follow the same diffusive pathway.

This is an unfortunate situation since the simple linear relationships between the two gaseous resistances for higher plants allows calculation of leaf internal carbon dioxide concentrations from water loss rates. This calculation is therefore not possible for lichens and no simple method appears to exist for obtaining thallus internal carbon dioxide concentrations. At high thallus water contents changes in $\sum r_{\mathrm{CO}_{2}}$ were not reflected by changes in $\sum r_{\mathrm{H}_{2} \mathrm{O}}$ so that increased resistance to carbon dioxide exchange did not mean a similar increase in desiccation resistance.

W. P. S. was in receipt of a University Grants Committee (UGC) post graduate scholarship, whilst T.G.A.G. received UGC grants for the purchase of equipment. The Urewera National Park Board and their staff are thanked for logistical support and permission to work in the park.

\section{REFERENCES}

Collins, C. A. \& Farrar, J. F. (1978) Structural resistances to mass transfer in the lichen Xanthoria parietina. New Phytol. 81: 71-83.

Cowan, D. A. Green, T. G. A. \& Wilson, A. T. (1979) Lichen metabolism. I. The use of tritium labelled water in studies of anhydrobiotic metabolism in Ramalina celastri and Peltigera polydactyla. New Phyrol. 82: 489-503.

Green, T. G. A. \& Snelgar, W. P. (1981) Carbon dioxide exchange in lichens: Partition of total $\mathrm{CO}_{2}$ resistances at different thallus water contents into transport and carboxylation components. Physiol. Plant. 52: $411-416$.

Green, T. G. A., Snelgar, W. P. \& Brown, D. H. (1981) Carbon dioxide exchange in lichens: $\mathrm{CO}_{2}$ exchange through the cyphellate lower cortex of Sticta latifrons Rich. New Phytol. 88: 421-426.

Harris, G. P. (1976) Water content and productivity of lichens. In Water and Plant Life-Problems and Modern Approaches, [Ecological Studies Vol. 19.] (O. L. Lange, E. L. Kappen \& E. D. Schulze, eds): 452-468. Berlin: Springer.

Jarvis, P. G. (1971) The estimation of resistances to carbon dioxide transfer. In Plant Photosynthetic Production: Manual of Methods (Z. Sestak, J. Catsky \& P. G. Jarvis, eds): 566-662. The Hague: Junk.

Jones, G. J. \& Norton, T. A. (1979) Internal factors controlling the rate of evaporation from fronds of some intertidal algae. New Phyrol. 83: 771-781.

Lange, O. L. (1980) Moisture content and $\mathrm{CO}_{2}$ exchange of lichens. Oecologia 45: 82-87.

Lange, O. L. \& Tenhunen, J. D. (1981) Moisture content and $\mathrm{CO}_{2}$ exchange of lichens II. Depression of net photosynthesis in Ramalina maciformis at high water content is caused by increased thallus carbon dioxide diffusion resistance. Oecologia 51: 426-429.

Larson, D. W. (1979) Lichen water relations under drying conditions. New Phytol. 82: 713-731.

Larson, D. W. \& Kershaw, K. A. (1976) Studies on lichen-dominated systems. XVIII. Morphological control of evaporation in lichens. Can. F. Bot. 54: 2061-2073.

Slavik, B. (1974) Methods of Studying Plant Water Relations. Berlin \& New York: Springer.

Snelgar, W. P. (1981) The ecophysiology of New Zealand forest lichens with special reference to carbon dioxide exchange. D. Phil. thesis, University of Waikato.

Snelgar, W. P. \& Green, T. G. A. (1981) Ecologically-linked variation in morphology, acetylene reduction and water relations in Pseudocyphellaria dissimilis. New Phytol. 87: 403-411.

Snelgar, W. P., Green, T. G. A. \& Beltz, C. K. (1981a) Carbon dioxide exchange in lichens: Estimation of internal thallus $\mathrm{CO}_{2}$ transport resistances. Physiol. Plant. 52: 417-422.

Snelgar, W. P., Green T. G. A. \& Wilkins, A. L. (1981b) Carbon dioxide exchange in lichens: Resistances to $\mathrm{CO}_{2}$ uptake at different thallus water contents. New Phytol. 88: 353-362. 